\title{
A Multidiscipline Approach to Governing Virtual Property Theft in Virtual Worlds
}

\author{
Nicholas C. Patterson and Michael Hobbs \\ School of Information Technology, Deakin University \\ Waurn Ponds, Victoria, 3217, Australia \\ ncp@deakin.edu.au, mick@deakin.edu.au
}

\begin{abstract}
The crime of virtual property theft has become a serious problem in virtual worlds in recent years. Players of these games are repeatedly falling victim to this crime, with little or no repercussion for the offender. Virtual property often has a substantial real world monetary value and the theft of such items impacts greatly on victims. The problem of virtual property theft is complex, involving many legal, regulatory and technological factors. As such, trying to address this problem in a single dimension is not sufficient, each factor need to be addressed with a multidisciplinary approach. In addressing this problem, this paper provides a model for describing the issue of virtual property trading and the issues associated with virtual property theft. The paper also proposes an approach for handling virtual property theft based on improvements to laws related to virtual property and theft, improvements to the virtual world software components and better regulation from governments.
\end{abstract}

Keywords: Virtual Property, Intellectual Property, Massively Multiplayer Online Games, Virtual Worlds, Virtual Property Theft, Real Money Trading.

\section{Introduction}

Virtual world games, often referred to as massively multiplayer online games, have evolved from traditional pen and paper based role playing games and that of networked multi-user dungeons or MUDs [1]. Game developers have extended the concept of MUDs, creating persistent worlds that continue to exist independent of any single player in the game, much like the real world [1]. In the context of this article the real world refers to activities that exist purely in real physical space where humans interact and a virtual world is everything that exists within digital space only. To define virtual worlds more explicitly; they are best described as an avenue for social interaction and a venue for hundreds of thousands of people to join together in exciting scenarios [2]. Virtual world games provide dynamic environments which allow individual game players to personalize their game experience through the collection of in-game items, completion of quests and the interaction with other game players. These virtual worlds usually have an active economic system [2], which provides players with an additional dimension to relate to the game. It is important to note that within the environments of virtual worlds, interaction between players is controlled 
by the developers and maintainers of the game and not by the players - which is both a key ingredient in the creativity of such environments but also a key cause of the problems that underlie virtual property theft.

Game developers can personalize a player's experience in a virtual world by allowing things such as a unique game character and allowing players to own virtual property; this can help promote a player's psychological bond to the game. The attachment a player has to their game character and its possessions not only holds a personal value for the game player but can also hold a real world monetary value. This value is the result of an investment of time, effort, skill and even real world money; a value that is able to be exchanged or even stolen.

Virtual property theft has been become an urgent area of research for two main reasons [2]. Firstly, player ownership of virtual property within a game can create an impact in the real world, in the form of economic and legal consequences [2]. The second reason is that there is no agreement or foundation for ownership of virtual objects gained by players [2]. Most virtual worlds games have an economic system, allowing players to trade, buy or sell virtual property and involves large amounts of real world money [2]. In the context of this article virtual property theft involves the theft of property that exists purely in a digital space or environment; this differs to traditional theft where it involves the theft of an actual, physical item.

There are currently over 100 virtual world games in existence, in different stages of development or operation [3]. Some of these virtual worlds have great numbers of active players, for example World of Warcraft, which is currently the most popular MMOG (massively multiplayer online game) claims to have more than 10 million users worldwide [3]. The large number of games and game players highlights the urgency of finding a solution to the problem of virtual property theft.

Within this article the enlisting of multiple strategies is proposed to achieve a solution to the problem of virtual property theft. The reasoning for this is that virtual worlds are complicated environments where a single solution may not be effective enough in defeating the problem of virtual property theft. These strategies will come in the form of legal, regulatory and software-security based solutions. The contribution of this article will give readers an informed view of how players interact with virtual world games as well as displaying how they function. Readers will discover what virtual property theft entails and what laws and regulations exist that can help protect the stakeholders from this crime. Finally, an outline of a multidiscipline approach to solving the problem of virtual property theft is presented. To achieve this goal, the paper is structured as follows. Section 2 provides a model of a virtual property trading system outlining the mechanics of virtual worlds and how players interact and trade virtual property. Section 3 discusses the issues of the game code complexity and the laws related to virtual property ownership and theft. Section 4 presents a multidisciplinary approach to addressing virtual property theft in virtual world games. While, Section 5 provides concluding remarks.

\section{A Model of a Virtual Property Trading System}

Virtual world games are rich, complex environments that provide the players of these games a diverse range of experiences and enjoyment. The concept of virtual property 
plays an important role in the support of player enjoyment. To simplify the discussion on this topic and to help highlight the issues associated with virtual property in virtual world games, the presentation and description of a generalized model can be useful.

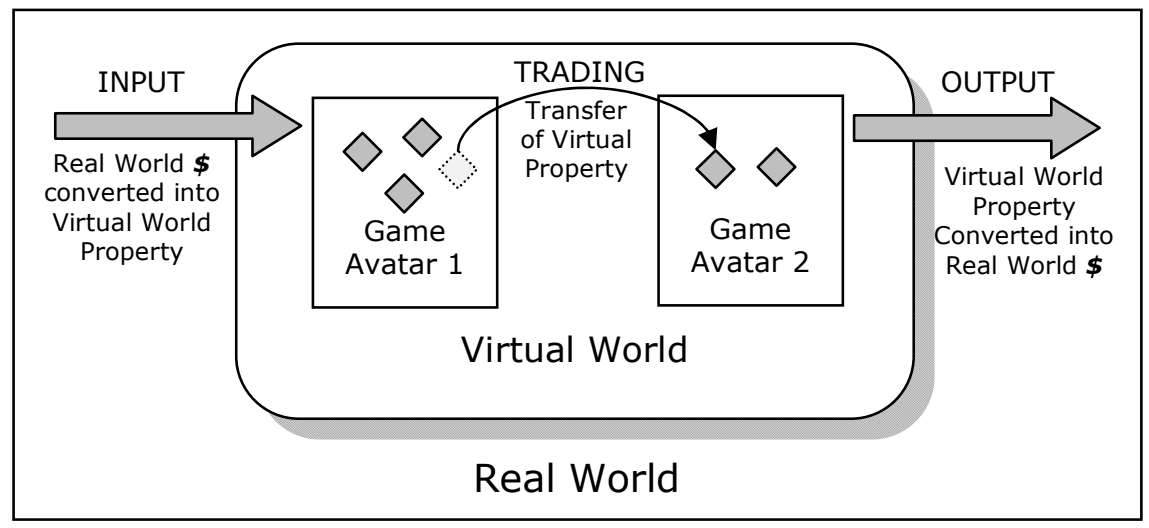

Fig. 1. A model of Virtual Property Trading in a Virtual World Game

The model presented in Figure 1 is an original representation of how the authors believe virtual property trading occurs within a virtual world game. The key features of this model include: the virtual world and the entities that represent game players in the game (referred to as Game Avatars in the figure); the possessions of the game players (Virtual Property); the mechanisms to transfer virtual property between players (Trading); and finally, the interface between the virtual and real worlds (Input and Output). The following sub-sections will expand and elaborate on each of these features, highlighting the potential risks for game players of experiencing virtual property theft.

\subsection{Virtual Worlds and Avatars}

The virtual world, represented in games such as World of Warcraft [4] and virtual environments such as Entropia [5] and SecondLife [6] is the result of the creative and technical efforts of game designers and developers. These environments are large, complex software applications that are specifically designed to support many hundreds of thousands of concurrently active game players in the virtual world. The game designers and developers provide the environment or platform in which game players can interact. The game play rules and permitted activities are written in software code and controlled through system configuration parameters (e.g., availability of game resources, difficulty levels of in-game tasks, challenges and or opponents).

The level of detail of these virtual worlds, along with the ability for players to customize their avatars and existence in the virtual worlds, are among the key factors which attract people to such environments. The level of attachment players have to their avatars and the virtual property items they acquire forms the foundation for the degree of impact a player can experience when virtual property they possess (in which 
they have a great personal or financial investment in) is taken away from them. The methods of how virtual property is acquired and transferred between players (which are core to the issue of virtual property theft) are detailed in the following sub-sections.

\subsection{Virtual Property Acquisition}

There are two possible methods a player is able to gain possession of virtual property in a virtual world game. In the first case, a player can earn virtual property through activities performed in the game. These relate to the game play rules determined by the games designers and can take a variety of forms, including: defeating various ingame enemies, where the defeated opponent drops various virtual property items that can be collected by the victor and performing in-game quests or missions which can be rewarded with virtual property items once finished successfully. Most virtual world games also have non-player characters who sell virtual items, so a player can buy these directly for a set amount of virtual currency. The last means of acquiring items involves real world currency and buying specific items off an auction website.

The second method game players acquire virtual property is through making virtual property items using in-game tools. Once made, these virtual assets are introduced into the virtual world to be utilized by the game player or by other players; examples of these can range from avatar clothes or even buildings. Another means by which virtual property can be made (specific to some virtual world games) is through profession based skills of the avatars, such as a tailor or blacksmith. These skills allow the avatars to collect raw materials and be able to make virtual items for themselves or other players.

The investment in terms of time, effort, skill and even real world money, results in great value being placed on the virtual property items acquired by game players. $\mathrm{Ku}$ \& Gupta [7] support this position by stating that they strongly believe that virtual property gathered within these games such as currency, swords, armor and jewelry not only contain an in-game value but also have value in real world economic markets. They also provide an indication [7] of the 'value' of virtual property, examples include a high level virtual character in the world of the popular game Lineage [8] can fetch upwards of \$800 USD and in a Yahoo [9] auction for a Mahjong account with 3 million Mahjong currency will fetch around the same price of \$800 USD. In the first week of January 2010 a virtual space station in the virtual universe Entropia sold for $\$ 330,000$ USD [10].

\subsection{Transfer Mechanics of Virtual Property}

It is common for game play rules that govern a virtual world game, to support the transfer of virtual property from one avatar to another. Normally performed through a consenting trade mechanism these transactions are done with a benefit to both players. In some cases this transfer of virtual property is conducted without the consent of the virtual property owner, usually through deceit or by compromising the game players account. The methods available to the game players to trade virtual property, either with or without consent, vary between games and environments. These methods of trade are implemented as core features to the software code but not intended to enable 
virtual property theft; they simply allow for it to happen in the right scenario without any code modifications on a criminal's part.

In their book Intelligence and Security Informatics; Ku and Gupta [7] categorize online gaming crime to include: virtual property theft and robbery, fraud, kidnapping, threat, assault and battery, destruction of property, counterfeiting, receipt of stolen property, privacy violations, software piracy, extortion and gambling [7]. In an examination of 613 online gaming criminal cases, occurring during 2002 in Taiwan it was found that theft and fraud were the major type of online gaming crimes [11]. $73.7 \%$ of cases were charged with theft, while $20.2 \%$ were charged with fraud [11]. These criminal cases came from official crime reports, from different judicial or investigative authorities [11].

The implications of game players owning virtual property (that hold a real world value) combined with the potential for that property to be stolen highlights the need for some method of recourse if such a situation occurs. In the real world, such circumstances are governed by rules of law covering theft and crime - the application of these laws or the creation of new laws to cover virtual worlds is in its infancy. The issues related to laws governing virtual property theft are explored in Section 3.

\subsection{Interfaces between Virtual Worlds and the Real World}

Players have discovered that there is a real world value for virtual property items in online marketplaces [7]. Large amounts of real world money is paid to obtain specific virtual items they can use within the game [7], usually to gain some kind of advantage within the game, such as a harder hitting sword. The market place for virtual property has created the potential for profit through the bidding, selling, trading and exchanging those virtual items [7]. This is where the problem of virtual property theft arises, due to the large amounts of virtual property transactions within these virtual worlds, it has attracted the attention of computer criminals [7]. These computer criminals develop methods to perpetrate these virtual worlds through hacking, cheating and scamming to make money from the sale of virtual property [7].

The trade of virtual property items has become a lucrative business in South Korea [12], and many other countries, due to the increase in popularity of online games. Dozens of companies such as PlayerAuctions [13] and ItemBay [14] in the past few years have been established to provide a secure means to perform virtual property exchanges; whether it is paying real money for virtual property or simply trading one item for another [15]. PlayerAuctions deals purely in virtual objects mainly from the game EverQuest [16] and receives over two million hits a day and ItemBay which is the dominant virtual object trading site for the Korean market (from over 130 similar sites) is reported to have an annual revenue greater than that of the combined virtual worlds it services [17]. ItemBay take around 5 percent of the virtual property sales price purely as commission; in the year of 2006 they earned \$18.6 million USD in commission alone and \$5.8 million USD in net profit [12].

From 2002, the crimes associated with online gaming have become a significant problem. In Taiwan more than $37 \%$ of all criminal cases relate to online gaming [18]. This crime has spread across many Asian countries including China, South Korea, Japan and Singapore [18]. 


\section{Factors Relating to Virtual Property Ownership}

As shown in the previous section, the features of virtual worlds and the virtual property that can be acquired provide players with great enjoyment as well as the potential for real world financial rewards. These financial rewards also provide criminals with motivation to obtain virtual property without consent, known as virtual property theft. The issue of virtual property theft is complex because virtual world games not only contain game developer made property but also property that the players can acquire/create; a situation that blurs the ownership of these items. Compounding this problem, the complexity of the software code that implements the virtual worlds game play that supports both intentional and unintentional transfer of virtual property between game players. These issues of the game code complexity and the laws related to virtual property ownership and theft are detailed in the following sub-sections.

\subsection{Virtual World Software Issues}

Virtual world games have become a target for criminals who are looking for virtual items (such as in-game gold) because it contains real world value. These criminals deliberately break into players accounts, steal virtual property and virtual characters in the game and then sell them, usually on the black market, for thousands of dollars [19].

One plausible reason why computer criminals have opted into virtual world crime is that it brings less risk than traditional forms of crime, as there is little chance that police will be able to prosecute them for stealing a magic potion for example [19], even if they are caught. In the United States, among other countries, these criminals also benefit greatly from very loose or nonexistent virtual property laws [19]. It is believed game designers are reluctant to push for legal recognition of virtual property for fear of being held liable for theft [19].

Virtual world games inherent issues of any software based application. The authentication procedures of many of these games are often antiquated at best; they consist of two fields, login and password which are typed in manually and then a login button is pressed. These forms of authentication can be broken quite easily. Recovery of virtual property within these virtual worlds can also be quite difficult. This often is the result of just not having the functionality within the game to do this or when an item is lost or stolen it has to be tracked from the original source to the new source which can involve detailed and complex database operations. The last issue that is problematic on the software mechanics is not being able to detect when virtual property theft is occurring or when it has occurred for that matter; the alarm is often only raised when a player realizes their account has been broken into and virtual property has been stolen.

\subsection{Increasing Popularity of Virtual World Games}

The last few years have seen a massive spike in the popularity of virtual world games, there are reports stating that in the order of 100 million people worldwide are logging on to play within them [20]. The issue of virtual property theft becomes important mainly due to the huge growth in the video game market, it is stated in the DFC 
Intelligence report [21] that the worldwide online games market will grow from $\$ 3.4$ billion in 2005 to be well over \$13 billion in 2011 .

\subsection{Laws and Regulations Related to the Governing of Virtual Worlds}

There are few laws and regulations that are specifically written to cover actions that occur in virtual worlds, due primarily to the relatively new and evolving environment they present. Although there are a number of traditional areas of law that have a close relationship to virtual property ownership, which include laws that relate to the game developers, such as end user license agreements (EULA), and those that are related to the game player, such as intellectual property rights and unfair competition. Governments are also interested in real world money being turned over, with the view of applying traditional taxation regulations to virtual world transactions.

\section{Chinese Law Case Study}

To add an extra dimension of complexity to this issue, virtual worlds are commonly accessible over the internet, meaning that the virtual world may be hosted in another country to you, raising the question of which country has jurisdiction when a crime is committed. China for example, has developed laws that cater specifically to the virtual property theft as shown in the case Li Hongchen vs. Beijing Arctic Ice Technology Development Co. In 2003, a Chinese gamer sued the game company Beijing Arctic Ice Technology Development Co. and won after the virtual world game company which runs Red Moon (Hongyue) refused to restore his stolen virtual property [22]. Hongchen spent years and thousands of dollars building up a virtual arsenal in the game Red Moon and claimed that his virtual property was stolen by hackers [22]. The end result of this court case which was held in Chaoyang District Peoples Court in Beijing was that Arctic Ice was found negligent for allowing a hacker to access $\mathrm{Li}$ Hongchen's game account and alter the data that represented his virtual property. Therefore the court ordered Artctic Ice to replace the virtual property, so Hongchen could go ahead and use them again in the context of the game [22].

\section{End User License Agreements (EULA)}

The EULA (End User Licensing Agreement) is an agreement and set of terms the player must agree to and abide by before they can play the game. World of Warcraft [4] and Entropia [5] both enlisted the use of a EULA to manage virtual property and any other possible issues; for example not only are all game developer components owned by the game developers but they also own any content created by the players inside or outside of the game [3]. The virtual environment Second Life is different, in that players who create content can begin selling it to other players inside the game because they control the intellectual property rights of their creations. However Linden Labs [6] the creators of Second Life still impose some limitation such as having the right to delete any or all of your content and requiring you to license it to them and every other user of the game for free [3]. MacInnes [23] argues that game companies use the EULA in the hope that will protect themselves against litigation (the action of taking out a lawsuit against an individual); by stating in the agreement that "virtual property has no real world value". These agreements could easily be voided by the court system if they determine that the EULA is too one sided [24] or the virtual property obtained and earned by the player holds value or theft of virtual property caused by game security flaws. 


\section{Intellectual Property Rights and Laws of Unfair Competition}

Companies that are in the business of developing massively multiplayer online games receive copyright protection for their games and graphics, but this same copyright protection does not allow them to stop players from selling parts of the game; such as their character, currency or other virtual property [25]. In fact intellectual property law actually grants players property rights and the permission to sell the game characters they own and have established over time, along with any property those characters own [25].

One other avenue for players to take is trade dress protection which falls under the intellectual property umbrella and refers to how a product looks and feels or its packaging. It is defined as the entire image or overall impression of the packaging or presentation of a product or service that identifies the source or good or services [25]. Essentially if a product has a unique look in its packaging, it can be protected. So essentially if a virtual character or virtual property item has a unique look established by the player, they could potentially own the rights to it.

This law of unfair competition protects unregistered trademarks and also trade dress, allowing for a player's game character to qualify as an unregistered trademark or receive trade dress protection [25].

In order for a player to qualify for protection, they have to identify the source of the goods and services in the minds of the consuming public; it is important to note that the actual identity of the source is not needed only that the goods or services originated from a single anonymous source [25].

\section{Government Taxation Laws}

The United States Internal Revenue Service has declared it would be very difficult to administer the taxation of virtual property transactions [26], for two reasons. Firstly, the need to be able to track and reconstruct many small transactions and the second is placing a value on virtual transactions would be quite hard; many of these items have an in-game value which is controlled by the game designers; adapting the value of virtual property to the real world is difficult.

The U.S. Congress and other governmental entities are close to determining how to establish policies and regulations regarding the income that is made by these game players performing real money trading (turning virtual property into real money) [27]. One country in particular that has implemented a virtual property tax law is China. In 2005 it was reported that as many as 100,000 people were employed as professional virtual currency 'farmers' [28] and no doubt that number has increased now in 2009. The Chinese government declared that it will tax profits where transactions involve virtual currency [28]. This tax law enforces a $20 \%$ tax on the income from virtual currency sales by each individual seller.

\section{Proposal for a Multidisciplinary Approach to Addressing Virtual Property Theft}

In order to prevent instances of virtual property theft, there has to be some kind of deterrent. The role of a deterrent is to assist in stopping these individuals from performing future acts involving malicious activity. Deterrents can be in the form of taxation, government laws, end-user licensing agreements or private regulations. The 
more deterrents in place; the harder it can be for potential criminals to ignore them. The whole goal behind deterrents in criminal law is to discourage members of the public from committing criminal acts, purely through fear of punishment.

The governance of virtual worlds and stopping the crime of virtual property theft has to come in a multi disciplined approach as it is a complicated problem. Governing virtual worlds through legal and regulatory avenues is only part of an overall solution. There is still a need for other distinct software based security methods to be produced in further work. Should software based solutions be produced they will hopefully aim to improve the security of these virtual world games through a variety of methods, for example through more secure authentication techniques, the ability to detect and identify when virtual property theft has occurred possibly before the player even realises, and lastly, where the other modules fail; the ability to recover stolen virtual property by game administration staff in an efficient manner.

Regarding the legal options; firstly there needs to be property rights established for virtual property. Property rights to protect players property from being stolen by other players and loss of virtual property due to negligence or confiscation by game developers [3].

On the regulatory side, there needs to be clear cut rules and regulations when it comes to the EULA and game administrators who deal with complaints and breaches in the EULA need to be informed on the action to take in each specific offence, there should be no grey areas.

Lastly the legal system should be improved in order to be able to deal with the complexities of virtual worlds and virtual property. This would involve developing specific virtual world laws that deal with every possible crime that can occur within these worlds, whether it is the theft of virtual property or one of the other crimes discussed in section 2.3; in-game assault and battery for example.

\section{Conclusion}

Virtual world games and environments are vast and contain many virtual items that carry great economic value. Criminal perpetrators leave a trail of virtual and real world destruction in their wake; whether it is stealing another player's entire account, stealing virtual property or forcing game administrators to ban compromised accounts.

As real money trading of virtual property continues to increase in terms of economic growth; governments are starting to take notice and no longer ignore the issue. Governments may actually realize now that individuals are making significant untaxed revenue from selling in-game virtual property. There is strong motivation for legislation which can prohibit and deter individuals from performing virtual property theft and the sale of virtual property. The proposal presented in this article outlines a multidiscipline approach to the problem of virtual property theft in virtual world games. It covers the legal and regulatory side of the problem and also covers methods to combat the software side of the problem and to improve security; through improved authentication techniques, introduction of detection methods and lastly the ability to recover lost or stolen property back to the original owner. There needs to be a solution to this problem sooner rather than later to protect both individual players, game 
developers and any corporate entities who invest into virtual worlds. The proposal presented in this article and the future work in the form of the software based solutions to improve security and the ability to handle virtual property theft discussed above are to be conducted by the authors and could potentially diminish the problem significantly if not completely.

\section{References $^{1}$}

1. White, E.E.: Massively Multiplayer Online Fraud: Why the Introduction of Real World Law in a Virtual Context Is Good for Everyone. Northwestern Journal of Technology and Intellectual Property 6(2), 228-243 (2008)

2. Eriksson, A., Grill, K.: Who owns my avatar? Rights in virtual property. In: DiGRA Conference, pp. 1-7 (2005)

3. DaCunha, N.S.: Virtual Property, Real Concerns. ExpressO (2009),

http: / /works.bepress.com/nelson_dacunha/1/

4. Blizzard.Entertainment. World of Warcraft Community Site (1991), http: / / www. worldofwarcraft.com

5. MindArk. Entropia Universe (2009), http: / /www.mindark.com/entropia-universe/

6. Linden.Research.Inc. Second Life Official Site (1999), http: / / indenlab.com/

7. Ku, Y., Gupta, S.: Online Gaming Perpetrators Model. In: Yang, C.C., et al. (eds.) Intelligence and Security Informatics, ISI 2008 Workshops, pp. 428-433. Springer, Heidelberg (2008)

8. NCSoft. Lineage - Popular fantasy MMORPG from NCSoft (2009), http: / /www. lineage.com/

9. Yahoo.Inc. Yahoo! (1994), http: / / us .yahoo.com/

10. Thier, D.: Virtual Space Station Sells for Price of an Actual House (2010), http: / /www .aolnews.com/nation/article/virtual-space-stationsells-for-price-of-an-actual-house/19305309

11. Chen, Y.-C., et al.: An analysis of online gaming crime characteristics. Internet Research 15(3), 246-261 (2005)

12. Jin-seo, C.: Hackers Paralyze Web Sites of Game Money Trading Firms (2007),

http://www. koreatimes.co.kr/www/news/biz/

biz_view.asp?news $I d x=11821 \&$ categoryCode $=123$

13. PlayerAuctions. PlayerAuctions - Play. Trade. Dominate (2009), http: / / www.playerauctions.com/

14. ItemBay. Professional online game virtual currency supplier and buyer and seller of game accounts (2005), http: / / www . itembay. ca/

15. White, E.E.: When Pretend Money Has Real Value: A Study of Virtual Property in Online Gaming. Northwestern Journal of Technology and Intellectual Property \& Technology Law Journal 6(2), 228-243 (2008)

16. Sony.Online.Entertainment. Sony Online Entertainment LLC (SOE) (1995), http: //www. station. sony.com/sonyonline/

17. Bartle, D.R.A.: Pitfalls of Virtual Property. The Themis Group, pp. 1-22. The Themis Group Incorporated. Durham, North Carolina (white paper) (2004)

\footnotetext{
${ }^{1}$ All websites checked and accessed on $1^{\text {st }}$ February 2010.
} 
18. Chen, Y.-C., et al.: Online Gaming Cheating and Security Issue. In: Cantarella, J.D. (ed.) Proceedings of the International Conference on Information Technology: Coding and Computing (ITCC 2005), vol. I(1), pp. 1-2. IEEE Computer Society, Los Alamitos (2005)

19. Spring, S.: Virtual Thievery. Newsweek (Atlantic Edition) 148(24), 10 (2006)

20. Kane, S.F.: Virtually Lawless: Legal \& Economic Issues in Virtual Worlds. Computer \& Internet Lawyer 25(6), 13-24 (2008)

21. DFC.Intelligence, Virtual Property and Real Money Trade: A Business and Legal Survey, pp. 1-55. DFC Intelligence, San Diego, (2009)

22. Meehan, M.: Virtual Property: Protecting Bits in Context. In: Richmond Journal of Law and Technology, pp. 7-48. University of Richmond School of Law (2006)

23. MacInnes, I.: The Implications of Property Rights in Virtual Worlds. In: 10th Americas Conference on Information Systems, New York, pp. 2727-2723 (2004)

24. Dougherty, C., Linden, B.v.: Virtual Property Rights Litigation. E-Commerce Law \& Policy 9(7), 1-5 (2007)

25. Stephens, M.: Sales of in-game assets: An illustration of the continuing failure of intellectual property law to protect digital-content creators. Texas Law Review 1513(80) (2002)

26. Internal. Revenue. Service, National Taxpayer Advocate. In: 2008 Annual Report to Congress, pp. 336. Internal Revenue Service (2008)

27. Mennecke, B., et al.: It's Just a Game, or is It? Real Money, Real Income, and Real Taxes in Virtual Worlds. Social Science Research Network (2007)

28. Zhang, B., et al.: China Taxes Real Profits from Virutal World Transactions. In: Pillsbury Winthrop Shaw Pittman LLP. Pillsbury Law, New York (white paper) (2008) 